\title{
Edible medicinal plants against COVID-19 in the Middle East
}

\begin{abstract}
All of humanity is inflicted by COVID-19 that is a pandemic respiratory illness, caused by a highly infectious form of novel Coronavirus, SARS-CoV-2, discovered at the end of 2019. Some of the typical symptoms of COVID-19 patients, includes fever, dry cough, shortness of breath, acute respiratory distress syndrome, the loss of taste and smell. Herbal medicines have been traditionally used to treat cold and flu symptoms, as well as diseases of the respiratory system. Certain medicinal foods could be used as a therapy or to prevent infection and as well strengthen immunity. Many people believe that consuming herbal immunomodulators can prevent or even treat COVID-19. Many foods and herbs are also known to display antiviral and immunomodulatory activities, these immunomodulatory herbs could enhance the immune system and protect the body against COVID- 19. This paper describes 16 medicinal food plants that are used traditionally to prevent or treat viruses and other diseases, including COVID-19, and strengthen the immune system.
\end{abstract}

Volume 14 Issue 3 - 202 I

\author{
Aref Abu Rabia \\ Ben-Gurion University of the Negev, Israel
}

Correspondence: Aref Abu Rabia, Ben-Gurion University of the Negev, Beer-Sheva 84I05, Israel, Email arefabu@gmail.com

Received: March 24, 2021 | Published: June 02, 2021

Keywords: edible, plants, food medicine, medicinal plants, medicinal foods, herbal medicine, Middle East, COVID-19

\section{Introduction}

COVID-19 is a pandemic respiratory illness caused by a highly infectious form of novel Coronavirus, SARS-CoV-2, discovered at the end of 2019. Most of the people infected with the SARS-CoV-2 virus will experience mild to moderate respiratory symptoms and may recover without requiring special treatment. ${ }^{i}$ The elderly and those with pre-existing medical conditions, such as cardiovascular disease, diabetes, chronic respiratory disease, and cancer are more likely to develop serious illness from SARS-CoV-2. ${ }^{\text {ii }}$ The typical symptoms of COVID-19 patients, includes fever, dry cough, shortness of breath, muscle aches, confusion, acute respiratory distress syndrome, as well as the loss of taste and smell. Additionally, these symptoms may be accompanied by fatigue, headache, diarrhea, lymphopenia; ${ }^{\text {:ii }}$ catarrh, nasal congestion, runny nose, sore throat, and sneezin;,iv,y,ivivii Various claims have been made about the pros and cons of herbal medicines in the prevention and treatment of COVID-19. ${ }^{\text {viii }}$ Historically, herbal medicines have been traditionally used to treat cold and flu symptoms, as well as other diseases of the respiratory system. Certain foods and herbs could be used as dietary or supplementary therapy to prevent infection and strengthen immunity. ${ }^{\mathrm{ix}}$ The longstanding use of dietary therapy and herbal medicine to prevent and treat diseases cannot be overemphasized, as several herbs do exhibit antiviral activity. ${ }^{\mathrm{x}}$ Treating influenza and the common cold with very large amounts of vitamin $\mathrm{C}$ has been practiced for decades; therefore, vitamin $\mathrm{C}$ may be effective against COVID-19. ${ }^{\text {xi }}$ Evidence has also shown that vitamin D may decrease the risk of developing severe symptoms from COVID-19. Thus, by extension, an increased vitamin D intake may reduce the risk of influenza and COVID-19 infections and related deaths. ${ }^{x i i}$ Many foods and herbs ${ }^{\text {xiii }}$ are also known to display antiviral and immunomodulatory activities ${ }^{x i v, x v}$ these immunomodulatory herbs could enhance the immune system and protect the body against COVID- 19. The current literature carries strong evidence in support of dietary therapy and herbal medicine as preventive agents against COVID-19, as well as for strengthening immunity. Aromatherapy and vaporized essential oils of certain herbs ${ }^{\mathrm{xvi}}$ have also been used for thousands of years ago as anti-microbial and anti-viral agents in preventing the spread of airborne bacteria and viruses. ${ }^{\text {xvii }}$ Many of these vaporized essential oils may provide therapeutic benefits for people suffering from influenza or other respiratory viral infections. . $^{\text {xviii }}$ Thus, using essential oils could be a good way to prevent COVID-19.

\section{Allium cepa L.}

Family: Liliaceae

Arabic: Basal

English: onion

Plant parts: leaves, bulb.

Preparation: Fresh, dried, or cooked.

Chemical constituents: quercetin, glucokinin, pectin, essential oil $^{\text {xix }}$ vitamin $\mathrm{C}$, potassium, phosphorus, sulfur, and iron ${ }^{\mathrm{xx}}$ steroidal saponins and sapogenins, sulfur compounds (alkenyl cesteine sulphoxides), and flavonides (quercetin) ${ }^{\mathrm{xxi}, \mathrm{xxii}}$ Onions contain S-propenylysteine sulphoxides and S-methylycteine sulphoxides, and are a major source of flavonoids, ${ }^{\text {xxiii }}$ vitamin C, gluconin, and sex hormones. .xiv $^{\text {. }}$

Properties and Ethno-botanical uses: tonic, cardiac tonic, appetizer, and antiseptic; treat cough and fever. In Jordan, the bulbs, fresh leaves are an appetizer. Onion may be squeezed onto the hands or into the mouth and nose to prevent influenza, colds, and other epidemic diseases. Fresh green onion leaves are eaten as salad or with other food $^{x x y, x x v i}$ In Eastern Turkey, onions, and garlic are commonly consumed to strengthen the immune system, notably during the COVID-19 pandemic of 2020.

\section{Allium sativum}

Family: Liliaceae

Arabic: thoum, thum

English: garlic

Plant parts: leaves and cloves, bulbs.

Preparation: The fresh leaves and cloves, or dried cloves are edible.

Chemical constituents: alliin, essential oil, vitamins A, C, minerals (Karim and Quraan 1986:39; Khalifa 1998:201), phosphorus, sulfur, alliin, allicin, garlic oil. The chief constituent of garlic is the sulfur compound allicin, produced by crushing or chewing fresh 
garlic, which in turn produces other sulfur compounds: ajoene, mono, di-, and tri-allyl sulfides, and vinyldithiins. ${ }^{\text {xxvii }}$

Properties and Ethno-botanical uses Allium sativum is carminative, cholagogue, aphrodisiac, diuretic, and purgative. Garlic can be used in the treatment of toothaches, ear infections and rheumatism; Garlic also has antiseptic, bacteriostatic, and antiviral effects. In Jordan, it used as an anti-hypertensive, treatment for whooping cough and diseases of the circulatory system. Fresh green leaves/bulbs are commonly eaten with salad. It is also used to treat asthma, and joint inflammations. Allium sativum was found to have several antimicrobial compounds, as well as active antitumor elements such allicin and ajoene ${ }^{\text {xxviii,xxix }}$ bulbs treat respiratory problems. As noted previously in Eastern Turkey, the consumption of onions, alongside garlic is believed to strengthen the immune system during the COVID-19 pandemic of 2020 (Pieroni et al. 2020:5-9). Garlic is also shown to demonstrate antiviral activity against influenza virus. ${ }^{\mathrm{xx}}$ Garlic can also treat respiratory diseases, such as the common cold, the cough, and other symptoms related to influenza; ${ }^{\text {xxxi }}$ Garlic can also be used to treat chronic bronchitis and upper respiratory tract infections. ${ }^{\text {xxxii }}$ Allicin-containing supplements can be taken as a preventative against the common cold virus, in the context of the COVID-19 pandemic.

\section{Althaea officinalis L.}

Family: Malvaceae

Arabic: khitmiya, khutmiya, Khutmiy

English: Marshmallow, White mallow

Plant parts: leaves, roots, flowers, seeds.

Preparation: The leaves can be eaten raw as salad, or soaked in water and eaten as a dish. The leaves and roots can also be boiled in water drank.

Chemical constituents: mucilage, starch, pectin, sugars, and asparagine, Vitamin C, tannin, and alum. Mucilage, flavonoids, phenolic acids, starch.

Properties and ethno-botanical use: Althaea officinalis is used as a calmative for cough, the crushed roots are boiled in water/ milk to treat fever, respiratory illnesses, coughing, throat infections, bronchitis, mucus secretions, asthma and spasmodic episodes. White Mallow can be made into an infusion for treatment of bronchial and throat catarrhs, and chronic coughs. ${ }^{\text {xxiii }}$ White Mallow is also an analgesic and anti-inflammatory. In Eastern Turkey, the use of Althaea spp. was recorded in cases of possible COVID-19 symptoms (shortness of breath and cough). White Mallow is also used as adjuvant in the treatment of early/mild cases of COVID-19. It is most useful in treating respiratory disease symptoms: dry, and irritable coughs, and irritations of oral and pharyngeal mucosa. .xxiv $^{\text {xan }}$

\section{Artemisia annua}

Family: Compositae (Asteraceae)

Arabic: shih hawli

English: annual wormwood/sweet wormwood/mug wort

Plant parts: Dried aerial parts, dried leaves, stalks.

Chemical constituents: arteannuin, peroxide group, misiaketone, cadinene, caryophyllene, chryososplenol, scopolin, scopoletin, ginghao acid, artemisinin, chloroquine, ${ }^{\mathrm{xxx}}$ essential oils, flavonoids and coumarins; the main chemical constituents are sesquiterpenoids, including artemisinin. ${ }^{\text {xxxi }}$

Properties and ethno-botanical uses: Artemisia annua is an antipyretic, ${ }^{\text {xxxvii }}$ antibacterial and anti-inflammatory traditionally used in the treatment of autoimmune diseases and malaria. It is still used in Asia and Africa to treat malaria ${ }^{\text {xxviii }}$ as well as COVID-19 symptoms.

\section{Artemesia herba-alba Asso}

Family: Compositae

Arabic: Shih, sheeh

English: Wormwood

Plant parts: Leaves, flowers.

Chemical constituents: essential oil, resin, pinene, cadinen, tannin; Santonin, sterols and thujones; it also contains essential oils, sesquiterpene lactones and thymol; the leaves and stems contain three non-glycosidic flavonoids, volatile components (monoterpene, Verbenol) (Bnouham 2012: 1-9). Properties and Ethno-botanical uses: Artemisa herba is a tonic, used to treat cough and colic (maghs). In Egypt and North Africa, an infusion of the flowering branches are tonic, carminative for the stomach, and used a cure for nervous troubles and 'calming the emotions'. In Jordan, it is used to treat inflammation, and asthma, the common cold, kidney stones and the cough.

In Jordan and Palestine, Artemisia herba is used to treat the cold, coughing (also the chronic cough), sore throat, lung infections, fever, influenza, loss of appetite, malaria, and as a treatment for COVID-19 symptoms. .xxix $^{x}$

\section{Citrus limon L.}

Family: Rutaceae

Arabic: laimun, laymun, hamid, laymon hulu

English: Lime, common lemon, Lemon

Plant parts: fruit, leaves and flowers.

Preparation: drink with water or tea.

Chemical constituents: Essential oil, vitamin C, hesperidin (Karim and Qura'an 1986:40); magnesium and phosphorus; limonoids, citronellal, volatile oil, citro-flavonoids, and citric acid, B6, riboflavine, calcium, iron, and potassium.

Properties and ethno-botanical uses: Citrus limon has antiemetic, appetizer, and anti-nausea properties, and is used in the treatment of malaria, and fever, it is also used in the treatment of colds.

During the 2020 Covid-19 pandemic in Milan, Italy, an increase in the consumption of some specific fresh fruits-especially, citrus fruitswas observed; it seems that this was one of many changes in food consumption habits adopted to treat COVID-19.

Citrus limon is also used to relieve cough and as expectorant for bronchitis, and as anti-inflammatory. It is also used to relieve respiratory symptoms, such as coughing and the sore throat, in the context of the COVID-19 pandemic.

\section{Commiphora myrrha (Nees)}

Family: Burseraceae

Arabic: mur, myrrh, subr, Mur batarikh.

English: Myrrh

Plant parts: resin.

Chemical constituents: the oleo-gum-resin contain volatile oil, resin, and gum. The constituents of Myrrh's volatile oil include terpenes, sesquiterpenes, esters, cumic aldehyde and eugenol. The sesquiterpene fraction contains furanosesquiterpenes: furanogermacranes, furanoguaianes and furanoeudesmanes. The gum contains protein, and carbohydrates of galactose, arabinose and glucuronic acid units. Sandaracopimaric acid, abietic acid, dehydroabietic acid. ${ }^{\mathrm{xl}}$ 
Properties and ethno-botanical use: Myrrh is used in the treat asthma, coughing, wounds, and hemorrhoids. In Yemen, the resin is burnt and the smoke allowed to rise between the legs of women postchildbirth to assist with the expulsion of the placenta and stimulate bloodflow (Ghazanfar 1994: 65). It has also been used to treat chest pains. ${ }^{\text {xli }}$ Myrrh is an exudate from the bark of the plant, which has therapeutic properties supporting its medicinal use (Singh 2015: 50-

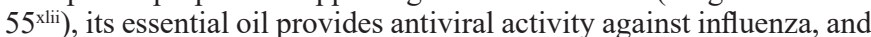
herpes.). The extract of Myrrh is believed to treat respiratory diseases like chest infections, and there is a possibility that Myrrh could be effective in treating the current cases of COVID-19. . $^{\text {liii }}$ It is used in the alleviation of respiratory symptoms such as the inflammation of pharyngeal mucosa; as well as an adjuvant in the treatment of early/ mild cases of COVID-19 (Silveira et al. 2020: 8, 30).

\section{Eucalyptus globules}

Family: Myrtaceae

Arabic: Kina, Kineih, Kafour

English: Eucalyptus, Blue gum tree

Part used: Leaves.

Active constituents: Cineol (eucalyptol) pinene, essential oil, resin and tannin.

Properties and ethno-botanical use: The essential oil of Eucalyptus globules is oestrogenic, antiseptic, expectorant, and an anti-inflammatory treatment for the upper respiratory tract and for skin diseases. It is also used in the treatment of dysentery, malaria, cough, stomach aches, diarrhea, nausea, fever, flu and the common cold. The use of Eucalyptus has been recorded in possible cases of COVID-19 (for symptoms including shortness of breath and cough) Eucalyptus globules is also used as an adjuvant in the treatment of early/mild cases of COVID-19. It is an effective treatment for the following respiratory disease symptoms: dry coughs, throat irritation, and irritations of oral and pharyngeal mucosa ${ }^{\text {xliv }}$

\section{Glycyrrhiza glabra $\mathbf{L}$.}

Family: Fabaceae (Leguminosae)

Arabic: 'irq al-sus, 'ud al-sus

English: Liquorice, licorice

Plant parts: root, leaves, rhizome, gum.

Active constituents: Glycyrrhizin asparagine, liquirtin, coumarin, sugar, tannin, glycyrrhizin and glycyrrhetic acid. Glycyrrhiza glabra is a source of licorice, the sweet taste is due to glycyrrhizin (the calcium and potassium salts of glycyrrhizinic acid); flavonoids, starch, protein and bitter principles. The plant also contains protein, sulphur, calcium oxalates, and resin. Glycyrrhizin, glycyrrhetinic acid, flavonoids (liquiritin, isoliquiritin).

Properties and ethno-botanical use: Glycyrrhiza glabra is used as an expectorant, and antitussive. It is also used in the treatment of peptic ulcers, hypertension, as an anti-inflammatory, diuretic, and is useful for the treatment of peptic ulcers. In Palestine, Glycyrrhiza glabra is used to treat coughs, lung infections, throat infections, infections of the urinary system, a sedative nervous system, and in the treatmen of fevers, and asthma. In Yemen, the plant is used to increase sexual potency. The root is used in the treatment of ulcers and painful coughs. The Glycyrrhiza glabra root also demonstrates antiviral activity against influenza. ${ }^{x l v}$ It is used in the treatment of the respiratory disease symptoms of coughing, sore throat and asthma. It is also an adjuvant in the treatment of early/mild cases of COVID-19.

\section{Malva sylvestris $\mathbf{L}$.}

Family: Malvaceae

Arabic: khubiza, khubaiz, khubizah
English: common mallow, blue mallow

Plant parts: leaves, shoots, seeds and flowers.

Chemical constituents: malvine, tannin, mucilage sterols, terpenes, anthocyanins, beta-carotene, malvidin, leucuyanidins, mucilage.

Properties and Ethno-botanical use: Malva sylvestris is calmative, laxative and an emollient. It is used in the treatment of abscesses, aphthas, asthma, inflammations of the mouth, constipation, teeth ailments, bleeding, the nerves, throat infections, coughing, and eye inflammations. The leaves are used as a laxative, antitussive and emollient for the intestinal mucosa, as well as a treatment for urinary tract diseases, vaginal infections, and provides relief from skin irritation. It is also used in the treatment of colds, and cough. ${ }^{\text {xlvi }}$ In Spain, a decoction of the roots are used orally for fever and to calm cough.

It is used in the treatment of respiratory diseases for pharyngeal irritation and dry coughs. ${ }^{x l v i i}$ and may be useful in the relief of COVID-19 symptoms by exerting a soothing effect on the respiratory tract (Silveira et al. 2020: 13-14).

\section{Nigella sativa $\mathbf{L}$.}

Family: Ranunculaceae

Arabic: habbit al-barakah/ haba sawda, qazha

English: Nigella, black cumin

Plant parts: seeds or extracted oil.

Chemical constituents: Essential oil, fixed oil, nigellin, saponin, nigellimine $\mathrm{N}$-oxide, and isoquinoline alkaloid. ${ }^{\text {xlvii }}$

Properties and ethno-botanical uses: Nigella sativa is used as a digestive, diuretic, emmenagogue, galactagogue, and carminative. The seed is used to relieve flatulence, increase milk secretion, treat arthritis, general weakness, the common cold, and gynecological disorders. According to the Prophet Muhammad, it can treat warts, asthma and moles. ${ }^{\text {xlix }}$ It also used as a liver tonic, a digestive, an antiinflammatory, immuno-stimulant, and remedy for jaundice. It can be used for the relief of a severe cough and for asthma in the context of COVID-19.

\section{Ocimum gratissimum $\mathbf{L}$.}

Arabic: raihan

Family: Lamiaceae

English: clove basil

Plant parts: leaves, seeds, roots, entire plant, whole plant.

Properties and ethno-botanical use: In West Africa, the leaves of Ocimum gratissimu are used for fever, dysentery, cough, headaches, snake bite, rheumatism and lumbag.

In India the plant is used to treat paralysis, neuralgia, rheumatism, gonorrhea, and headache. ${ }^{\mathrm{li}}$

In West Indies, fresh leaves in tea are used to treat the flu, fever, pneumonia, and dysmenorrhea. It is bactericidal and anthelmintic. lii

It can also be used to treat symptoms of cold, influenza, fever, asthma, and bronchitis. ${ }^{\text {liii }}$ Its antitussive properties may allow for its potential use in the relief of early symptoms of COVID-19. liv

Pimpinella anisum L./Anisum vulgare $\mathbf{L}$.

Family: Umbelliferae (Apiaceae)

Arabic: yansun, anisun

English: Anise, aniseed 


\section{Plant parts: Seeds and flowers.}

Chemical constituents: essential oil, anethol, fixed oil, choline, mucilage, limonene, and rosin (Karim and Qura'an 1986:39; Khalifa 1998:601). Flavonoids isolated from anise include quercetin 3-glucuronide, rutin, luteolin 7-glucoside, isoorientin, isovitexin, apigenin 7-glucoside and a luteolin glycoside. . $^{\text {vvlvi }}$ Anise also contains aflatoxin, mycotoxin, acetaldehyde, alpha-pinene, alpha-terpineol, squalene, stigmasterol, trans-anethole, and zinc. lvii,lviii,lix $^{2}$

Properties and ethno-botanical uses: Pimpinella anisum has anti-spasmodic, aromatic, bronchodilator, carminative, diaphoretic, diuretic, properies, and can be used as a flavoring agent. Its diuretic properties make it an effective treatment for urinary tract infections and urine retention. The fruits are used to treat the common cold, and general weakness. In Palestine, the plant is used to treat stomach and intestinal pain, headaches, to increase fertility, and symptoms associated with the common cold and respiratory illnesses. The main constituent of the essential oil of anise is anethol, is an active estrogenic agent, and has been shown to block inflammations due to its antioxidant and anti-inflammatory properties. ${ }^{1 \mathrm{x}}$ The plant is also used the treatment of fevers and coughs, and thus, might be effective in the relief of the early symptoms of COVID-19 (Silveira et al. 2020:15-16).

\section{Sambucus nigra $\mathbf{L}$.}

Family: Caprifoliaceae/Adoxaceae

Arabic: bailassan, khamman, khaman kabir, sabuqah

English: black elder

Plant parts: berry, flower, bark, fruit, leaves.

Chemical constituents: Sambucin, sambunigrine, resin, tannin, tyrosin, essential oil; vitamin A and C; Iron, phosphorus and potassium, mucilage, flavonoids, anthocyanique. Anthocyanins (sambucin, sambucyanin), flavonoids, essential oil, ascorbic acid, phenolic acids, triterpenes (Bone 2007: 32).

Properties and ethno-botanical use: Sambucus nigra is a depurative, laxative, diuretic, calmative, and sedative, commonly used in the treatment of rheumatism, nervous system disorders, the common cold and inflammations of the respiratory system. Sambucus nigra is also used for treating coughing and flu, fever, and headaches. It can be used as an adjuvant in the treatment of early/mild cases of COVID-19.

\section{Thymus vulgaris $\mathbf{L}$.}

Family: Lamiaceae (Labiatae)

Arabic: $z a$ 'atar

English: Thyme

Plant parts: leaves, flower, the whole herb.

Chemical constituents: volatile oil contains phenols, including thymol, carvacrol, glycoside, and flavonoids, tannin, resin and saponoside. Its essential oil mainly includes phenols (such as thymol, carvacrol), carnosic acid, biphenyls, flavonoids, phenolic acids, acetophenone glycosides.

Properties and ethno-botanical uses: Thymus vulgaris has aphrodisiac, antispasmodic, and carminative properties. It is used in afterbirth, care, as a treatment for disorders of the digestive and respiratory systems, ulcerous migraines, whooping cough, asthma, and colic. It is one of the most commonly used spices in the Arab kitchen.

In Jordan, the shoots of the plants are used to treat hypertension, the common cold, abdominal pain, and as a blood purifier. Thymus vulgaris is also used to treat coughing associated with cold, laryngitis and tonsillitis. ${ }^{1 \times i}$ Because of its spasmolytic and anti-inflammatory properties, it may be useful for relieving the respiratory symptoms, associated with COVID-19.

\section{Zingiber officinalis}

Family: Zingiberaceae

Arabic: Zingibil, Zenjabil

English: ginger, East Indian ginger

Plant parts: rhizome.

Chemical constituents: the rhizome contains volatile oil and resin, starch and mucilage. The oil contains cineole, citral, borneol and sesquiterpenes (zingiberene and bisabolene); the rhizome contains gingerol, phenols, and zingerone. Phenolic volatile oils (gingerol analogues: gingerols, shogaol), gum, resin, volatile oil, resin oil, gingerin, calcium, vitamins $\mathrm{A}$ and $\mathrm{B}$, zingerone, shogaols, gingerols, paradols, wikstromol, and carinol. .xii $^{\text {lik }}$

Properties and ethno-botanical uses: Zingiber officinalis is a stimulant, analgesic and aphrodisiac. It is used to treat postpartum mothers by stimulating blood circulation and preventing clotting.

In Jordan, the rhizomes are used in treating anemia, the common cold, and for general weakness. It can also be used to treat a sore throat, infections of the lungs, eye inflammations, hoarseness and flatulence.

In North Africa, its powdered rhizome is an ingredient in a popular drug imported from Southeast Asia, for its stimulant and aphrodisiac properties. In Lebanon, postpartum mothers are given a drink consisting of ginger boiled with cinnamon and other hot spices to stimulate circulation and prevent blood clotting. Ginger is has also been shown to demonstrate antiviral activity against the influenza virus. In the context of the Covid-19 pandemic, its use as a treatment in anti-inflammatory therapy for upper respiratory affections as well as its uses in treating the common cold, coughing, and asthma may prove effective in dealing with some of the disease's respiratory symptoms.

\section{Conclusions}

Most of the institutionalized health services have struggled to combat the COVID-19 pandemic in its early stages. Although there are now several pharmaceutical companies with approved vaccines for this disease (and still more in development) unfortunately the cost of these vaccines prohibits many countries from carrying out vaccination campaigns among their populations. At the same time, there are numerous of medicinal plants, fruits and vegetable products that may very likely prove as effective adjuvants in preventing and treating the symptoms of COVID-19.

Furthermore Consuming healthy food produced from plants, fruits and vegetables, could enhance the immune system and protect the body against COVID- 19, as well as other viruses and diseases, and more broadly improve the general wellbeing of people. Thus, dietary therapy and medicinal plants should not be ruled out as a complementary preventive therapy, especially among at-risk populations with limited vaccine access during the COVID-19 pandemic. Far from being a pseudoscience, these therapies could exist side by side with modern/western medicine, and even enhance the effectiveness of western medical procedures. These edible medicinal plants contain a host of biologically-active compounds. Their physiological effects requires more research in future to improve our understanding of human nutritional and medicinal requirements, especially with reference to flu symptoms, diseases of the respiratory system, as well as COVID-19. 


\section{Acknowledgments}

None.

\section{Conflicts of interest}

The author declares that he has no conflict of interest.

\section{Funding}

None.

\section{Endnotes}

i. https://www.who.int/health-topics/coronavirus\#tab=tab_1

ii. World Health Organization (WHO). What are the symptoms of COVID-19? Geneva, Swizerland: World Health Organization. 2021.

iii. Lymphopenia/Lymphocytopenia is the condition of having an abnormally low level of lymphocytes in the blood. Lymphocytes are a white blood cell with important functions in the immune system (Stedman 2000: 1044-1047= Stedman's medical dictionary. 27th edn. London \& New York: Lippincott Williams \& Wilkins; 2000.

iv. Chen N, Zhou M, Dong $\mathrm{X}$, et al. Epidemiological and clinical characteristics of 99 cases of 2019 Novel Coronavirus pneumonia in Wuhan, China: a descriptive study. Lancet. 2020;395(10223):507-513.

v. Huang C, Wang Y, Li X, et al. Clinical features of patients infected with 2019 novel coronavirus in Wuhan, China. Lancet. 2020;395(10223):497-506.

vi. Rothan HA, Byrareddy SN. The epidemiology and pathogenesis of coronavirus disease (COVID-19) outbreak. J Autoimmun. 2020;109:102433.

vii. Silveira D, Prieto-Garcia MJ, Boylan F, et al. COVID-19: Is There Evidence for the Use of Herbal Medicines as Adjuvant Symptomatic Therapy? Front Pharmacol. 2020;11:581840.

viii. Nugraha RV, Ridwansyah H, Ghozali M, et al. 2020, Traditional Herbal Medicine Candidates as Complementary Treatments for COVID-19: A Review of Their Mechanisms, Pros and Cons. Evid Based Complement Alternat Med. 2020;2020:2560645.

ix. Panyod S, Ho CT, Sheen YN, et al. Dietary therapy and herbal medicine for COVID-19 prevention: A review and perspective. J Tradit Complement Med. 2020;10(4):420-427.

x. Panyod S, Ho CT, Sheen YN, et al. Dietary therapy and herbal medicine for COVID-19 prevention: A review and perspective. J Tradit Complement Med. 2020;10(4):420-427.

xi. Saul AW. Nutritional treatment of coronavirus. Orthomol Med News Ser. 2020.

xii. Grant WB, Lahore H, McDonnell SL, et al. Evidence that vitamin d supplementation could reduce risk of influenza and COVID-19 infections and deaths. Nutrients. 2020;12(4):988.

xiii. Aloe vera, Angelica gigas, Astragalus membranaceus, Panax ginseng and Scutellaria baicalensis Rice bran, wheat bran, Lawsonia alba, Echinacea purpurea, Plumbago zeylanica, and Eucalyptus essential oil (Tan and Vanitha 2004: 1423-1430; Saldon 2010: 33-42).

xiv. Tan BKH, Vanitha J. Immunomodulatory and antimicrobial effects of some traditional Chinese medicinal herbs: a review. Curr Med Chem. 2004;11(11): 1423-1430.

xv. Sadlon AE, Lamson DW. Immune-modifying and antimicrobial effects of eucalyptus oil and simple inhalation devices. Alternative Med Rev. 2010;15(1): 33-42.

xvi. Panyod. like Citrus bergamia, Eucalyptus globulus, Pelargonium graveolens (geranium), Cinnamomum zeylanicum leaf oil (cinnamon), and Cymbopogon flexuosus (lemongrass). 2020. xvii. Swamy MK, Akhtar MS, Sinniah UR. Antimicrobial properties of plant essential oils against human pathogens and their mode of action: an updated review. Evid-Based Compl Alt Med. 2016;3012462.

xviii. Vimalanathan S, Hudson J. Anti-influenza virus activity of essential oils and vapors. Amer J Essential Oil Nat Prod. 2014;2(1):47-53.

xix. Karim F, Qura'an S. Medicinal Plants of Jordan, Irbid: Yarmouk University; 1986.

xx. John L. The Herb Book. Turonto \& New York: Bantam Books; 1980

xxi. Sengupta A, Samit G, d Shamee B. Allium Vegetables in Cancer Prevention: An Overview. Asian Pac J Cancer Prev. 2004;5(3):237245.

xxii. Krest I. Glodek J, Keusgen M. Cysteine Sulfoxides and Alliinase Activity of Some Allium Species. J Agric Food Chem. 2000;48(8):7533760 .

xxiii. Arabbi PR, Genovese MI, Lajolo FM. Flavonoids in vegetable foods commonly consumed in Brazil and estimated ingestion by the Brazilian population. Agric Food Chem. 2004;52(5):2004:1124-1131.

xxiv. Al-Khalifah IS, Sharkas SM. Nabatat al-Kuwayt al-tibbiyah. 1984.

xxv. Abu-Rabia A. Herbs as a food and medicine source in Palestine. Asian Pac J Cancer Prev. 2005;6(3):404-407.

xxvi. Abu-Rabia A. Key Plants in Fighting Cancer in the Middle East. Chinese Medicine. 2015;6(20):124-135.

xxvii. Koch HP, Lawson LD. Garlic: The Science and Therapeutic Application of Allium sativum $\mathrm{L}$ and related species. $2^{\text {nd }}$ edn. Baltimore: Williams and Wilkins; 1996.

xxviii. Dirsch VM, Kiemer AK, Wagner H, et al. The effect of allicin and ajoene, two compounds of garlic, on inducible nitric oxide synthase. Atherosclerosis. 1998;139(2):333-335.

xxix. Singh A, Shukla Y. Antitumor activity of diallyl sulfide in two-stage skin model of carcinogenesis. Biomed Environ Sci. 1998;11(3):258263.

xxx. Rasool A, Khan MU, Ali MA, et al. Anti-avian influenza virus H9N2 activity of aqueous extracts of Zingiber officinalis (ginger) and allium sativum (garlic) in chick embryos. Pak J Pharm Sci. 2017;30(4):13411344.

xxxi. Form of Herbal Medicines of the Brazilian Pharmacopoeia. Brazil: National Health Surveillance Agency; 2011. p. 125.

xxxii. El-Saber Batiha G, Magdy Beshbishy A, Wasef LG, et al. Chemical Constituents and Pharmacological Activities of Garlic (Allium sativum L.): A Review. Nutrients. 2020;12(3):872.

xxxiii. Loutfy Boulos 1983, Medicinal Plants of North Africa, Algonac, Michigan: Reference Publications, Inc.

xxxiv. EMA 2016c, "European Union herbal monograph on Althaea officinalis L., radix," in EMA/HMPC/436679/2015 Committee on Herbal Medicinal Products (HMPC); London: European Medicines Agency.

xxxv. James D, Ayensu E. Medicinal Plants of China. Algonac, Michigan: Reference Publications, Inc; 1985.

xxxvi. World Health Organization (WHO). WHO monograph on good agricultural and collection for Artemisia annua L. 2005. an agent that reduces fever.

xxxvii. an agent that reduces fever.

xxxviii. Weathers PJ, Towler MJ. Cchanges in key constituents of clonally propagated Artemisia annua L. during preparation of compressed leaf tablets for possible therapeutic use, Ind. Crops Prod. 2014;62:173-178.

xxix. Personal communications 29 June, 15 July and 27, 30 September 2020

xl. Shimshon Ben-Yehoshua and Lumir Hanus 2014, Apharsemon, Myrrh and Olibanum: Ancient Medical Plants. In, Yaniv and Dudai, eds. 
xli. Al-Howiriny TA, Al-Sohaibani MO, Al-Said MS, et al Hepatoprotective properties of Commiphora opobalsamum (Balessan), a traditional medicinal plant of Saudi Arabia. Drugs Exp Clin Res. 2004;30(5-6):213-220

xlii. Singh R. 2015, Medicinal plants: A review. J Plant Sci. 2015;3(1):50-5.

xliii. Alyafei N. Can Myrrh Combat COVID-19? Ibero American Journal of Medicine. 2020;2(3):223-229.

xliv. EMA. European Union herbal monograph on Althaea officinalis L. radix," in EMA/HMPC/436679/2015 Committee on Herbal Medicinal Products (HMPC). London: European Medicines Agency. 2016.

xlv. Hoever G, Baltina L, Michaelis M, et al. Antiviral activity of glycyrrhizic acid derivatives against sars-coronavirus. J Med Chem. 2005;48(4):1256-1259.

xlvi. Rabia AA. Key Plants in Fighting Cancer in the Middle East Chinese Medicine. 2015;6(2):124-135.

xlvii. BRASIL. Formulário de Fitoterápicos da Farmacopeia Brasileira (Brasilia: Agência Nacional de Vigilância Sanitária).

xlviii. El-Obeid A, Al-Harbi S, Al-Jomah N, et al. Herbal melanin modulates tumor necrosis factor alpha (TNF-a), interleukin 6 (IL-6) and vascular endothelial growth factor (VEGF) production. Phytomedicine. 2006;13(5):324-333.

xlix. Al-Jawziyya, Ibn Qayyim. Medicine of the Prophet. In: Penelope Johnstone. Cambridge: The Islamic Texts Society; 1998.

1. Ayensu ES. Medicinal Plants of West Africa, Algonac, Michigan: Reference Publications, Inc; 1978.

li. Jain SK, Robert DeFilipps. Medicinal Plants in India, Algonac, Michigan: Reference Publications, Inc; 1991.

lii. Ayensu ES. Medicinal Plants of the West Indies, Algonac, Michigan: Reference Publications, Inc; 1981 1iii. World Health Organization (WHO). Monographs on selected medicinal plants 2. Geneva: World Health Organization; 2002.

liv. Silveira D, Prieto-Garcia JM, Boylan F, et al., COVID-19: Is There Evidence for the Use of Herbal Medicines as Adjuvant Symptomatic Therapy? Front Pharmacol. 2020;11:581840.

lv. Kunzemann J, Herrmann K. [Isolation and identification of flavon(ol)-Oglycosides in caraway (Carum carvi L.), fennel (Foeniculum vulgare Mill.), anise (Pimpinella anisum L.), and coriander (Coriandrum sativum L.), and of flavon-C-glycosides in anise. I. Phenolics of spices (author's transl)]. Z Lebensm Unters Forsch. 1977;164(3):194-200.

lvi. Gebhardt Y, Witte S, Forkmann G, et al. Molecular evolution of flavonoid dioxygenases in the family Apiaceae. Phytochemistry. 2005;66(11):1273-1284.

lvii. Burkhardt G, Reichling J, Martin R, et al. Terpene hydrocarbons in Pimpinella anisum L. Pharm Weekbl Sci. 1986;8(3):190-193.

lviii. El Kady IA, El Maraghy SS, Eman Mostafa M. Natural occurrence of mycotoxins in different spices in Egypt. Folia Microbiol (Praha). 1995;40 (3):297-300.

lix. Tabanca N, Demirci B, Ozek T, et al. Gas chromatographic-mass spectrometric analysis of essential oils from Pimpinella species gathered from Central and Northern Turkey. J Chromatogr A. 2006; 1117(2):194-205.

1x. Aggarwal BB, Shishodia S. Suppression of the nuclear factor-kB activation pathway by spice-derived phytochemicals. Reasoning for seasoning, Annals New York Academy of Sciences. 2004:434-441.

1xi. World Health Organization (WHO). Monographs on selected medicinal plants. Geneva: World Health Organization; 1999

1xii. Idris NA, Yasin HM, Usman A. Voltammetric and spectroscopic determination of polyphenols and antioxidants in ginger (Zingiber officinale Roscoe). Heliyon. 2019;5(5):E01717. 